\title{
Visual Technology for the Autonomous Learning of Mathematics ${ }^{1}$
}

\author{
Helmut Linneweber-Lammerskitten \\ University of Applied Sciences Northwestern Switzerland \\ helmut.linneweber@fhnw.ch \\ Marc Schäfer \& Duncan Samson \\ Rhodes University, South Africa \\ m.schafer@ru.ac.za \& d.samson@ru.ac.za
}

\begin{abstract}
This paper describes a collaborative research and development project between the University of Applied Sciences Northwestern Switzerland and Rhodes University in South Africa. The project seeks to establish, disseminate and research the efficacy and use of short video clips designed specifically for the autonomous learning of mathematics. Specific to the South African context is our interest in capitalising on the ubiquity of cellphone technology and the autonomous affordances offered by mobile learning. This paper engages with a number of theoretical and pedagogical issues relating to the design, production and use of these video clips. Although the focus is specific to the contexts of South Africa and Switzerland, the discussion is of broad applicability.
\end{abstract}

The use of both videos and video clips as a medium of learning and teaching is nothing new to the mathematics classroom. In our view, however, many of these videos are too long. Furthermore, they are often underpinned by predetermined specific outcomes and pedagogical imperatives. There is a lack of short, succinct video material that both teachers and learners alike can access swiftly and efficiently, and use autonomously.

The Visual Technology for the Autonomous Learning of Mathematics (VITALmaths) project has been established to fill this void (Linneweber-Lammerskitten \& Schäfer, 2010). Students at the School of Teacher Education at the University of Applied Sciences Northwestern Switzerland and mathematics education students at Rhodes University in South Africa have been developing a bank of video clips that unpack a variety of mathematical concepts. These video clips are all very short (1-3 minutes long) and specifically make use of natural materials (as opposed to high-tech animations) to animate and develop mathematical ideas and processes. Specific to the South African context, we are especially interested in making use of cellphone technology as the primary distribution platform for these video clips.

The implementation of a research agenda around the use of the video clips is currently being developed. Numerous groups of teachers and learners in both participating countries will participate in this research, and a broad spectrum of school contexts will be considered. The research questions surrounding the video clips are multifaceted but will focus on:

- their efficacy,

$\bigcirc$ their use by participating teachers and learners, and

$\circ$ their accessibility.

\footnotetext{
${ }^{1}$ This paper is an extension and elaboration of our previous report on the VITALmaths project (LinneweberLammerskitten \& Schäfer, 2010).
} 
This research agenda will in turn inform the design and production of the video clips through a cyclical and reflective process. The text in the video clips will also be translated into numerous languages, including indigenous languages, and it is anticipated that this will open up further interesting research arenas.

This paper engages with a number of theoretical and pedagogical issues relating to the use of video clips as a medium for teaching and learning mathematics. Although the focus is specific to the contexts of Switzerland and South Africa, the discussion will be of broad applicability.

\section{Exploration as an aspect of mathematical competence}

Among the implications that can be expected from the implementation of the National Educational Standards in Switzerland, as well as a number of other European countries, the following three appear to be most important for mathematics education (Linneweber-Lammerskitten \& Wälti, 2008):

- It will be necessary to find better ways to deal with heterogeneity - especially to provide more support for weaker pupils.

- It will be necessary to give more attention to the non-cognitive dimensions of mathematical competency, such as motivation, sustaining interest and the ability to work in a team.

- It will be necessary to deal with aspects of mathematical competence that were mostly neglected in the past - especially the ability and readiness to explore mathematical states of affairs, to formulate conjectures, and to establish ideas for testing conjectures.

These necessities find resonance with similar implications which have arisen from the implementation of the Revised National Curriculum Statement in South Africa. This is true not only in terms of subjectspecific outcomes and assessment standards, but it is also echoed by the social transformation imperatives of the curriculum and the desired attributes of the kind of learner envisaged within the South African education system (Department of Education [DOE], 2002, 2003).

According to the National Educational Standards in Switzerland, mathematical competence comprises the ability and readiness to investigate and explore, to formulate conjectures, and to establish ideas for testing conjectures. Of importance is that readiness, and other such non-cognitive dispositions, are considered constituent moments of the underlying notion of competence. The concept framework of the National Education Standards in Switzerland defines competencies as "...cognitive abilities and skills possessed by or able to be learned by individuals that enable them to solve particular problems, as well as the motivational, volitional and social readiness and capacity to utilise the solutions successfully and responsibly in variable situations" (Weinert, 2001, as quoted in Klieme et al., 2004, pp. 16-17). This definition is based on the notion that motivational, volitional and social readiness as well as capacity are not only seen as fostering factors for, but rather as constitutive parts of mathematical competence. This can be made clear by a terminological distinction between competence and skill:

A competence is defined as the ability to successfully meet complex demands in a particular context. Competent performance or effective action implies the mobilization of knowledge, cognitive and practical skills, as well as social and behavior components such as attitudes, emotions, and values and motivations. A competence - a holistic notion - is therefore not reducible to its cognitive dimension, and thus the terms competence and skill are not synonymous. (OECD, 2003, p. 2)

This is a valuable notion of competence to keep in mind when reading the South African Revised National Curriculum Statement for mathematics where the study of mathematics is seen to contribute to personal development "through a deeper understanding and successful application of its knowledge and skills, while maintaining appropriate values and attitudes" (DOE, 2003, p. 9). It is also worth noting the emphasis placed on mathematical exploration: "Competence in mathematical process skills such as investigating, generalising and proving is more important than the acquisition of content knowledge for its own sake" (DOE, 2003, p. 9). In terms of attitudes and dispositions, the teaching and learning of mathematics aims to develop (a) the confidence and competence to deal with mathematical situations without being hindered by a fear of mathematics, (b) an appreciation for the beauty and elegance of mathematics, (c) a spirit of curiosity, and (d) a love for mathematics (DOE, 2002, p. 4). Finally, it is significant that the curriculum seeks to create lifelong learners who are both confident and independent (DOE, 2002, p. 3). 
Bearing in mind that these educational standards and curriculum statements are representative of the minimum levels of knowledge and skills achievable at each grade, it follows that the establishment of such aspects of competence as minimal standards for all learners can only be successful if appropriate measures are taken to fully integrate weaker learners in the learning experience, and to create an environment that is stimulating, motivating, interesting and encourages social competence. Mathematical investigation and exploration presupposes a higher level of motivation and volition than any other aspect of competence, since it requires not only the ability and readiness for self-organised fulfilment of a job order, but also the motivation to start acting mathematically even if there is no external order do so. Furthermore, it requires a curiosity and a will to go beyond the mere results obtained. However, there is much evidence to suggest that weaker learners, particularly when they feel unsure, tend to prefer explicitly formulated work orders which according to their opinion define the beginning and the end of a mathematical activity.

\section{Motivating mathematical exploration through video clips}

The National Educational Standards in Switzerland and the Revised National Curriculum Statement in South Africa, especially in light of the various aforementioned implications, present both a challenge and an additional strain for future teachers that should not be underestimated. Learners with weaker mathematical ability - a group that in itself is far from homogenous - will require stronger assistance and support, while at the same time the average and high-ability learners should not be neglected. It will thus be necessary to establish additional instruments, new forms of supervision and teaching strategies on the one hand, and new learning environments and tools on the other to meet this challenge.

In accordance with the Mathe 2000 initiative in Germany (Wittmann, 1995), new learning materials for mathematics have been introduced in the last decade in almost the whole of the German-speaking part of Switzerland. Although the materials encourage learning environments for autonomous exploration, they still require support and motivational activities for weaker learners. This was the starting point and challenge for student teachers at the University of Applied Sciences Northwestern Switzerland - to search for the development of auxiliary means that could not only release teachers from the frontal introduction to mathematical themes on the one hand, but also to provide an opportunity for weaker learners to experience genuine and challenging mathematical activities. Students produced a series of short-length silent video clips illustrating and developing a variety of mathematical concepts. This initiative led to the genesis of VITALmaths.

The VITALmaths project seeks to establish and disseminate a freely accessible growing databank of short video clips designed specifically for the autonomous learning of mathematics. Common design principles of these video clips are that they are short, not too difficult to produce, are aesthetically delightful, and are self-explanatory - i.e. they require minimal instruction and are ready to be viewed and used to record observations, considerations and reflections in written form. The video clips do not require too much mathematical knowledge, nor do they make excessive intellectual demands which could lead to frustration. However, they nonetheless encourage genuine mathematical exploration that transcends the mere mathematical content of the film by encouraging a desire to experiment, use trial-and-error, formulate conjectures, and generalise results. A dedicated website ${ }^{2}$ has been established to house this growing databank of video clips from which the video files can either be freely downloaded or streamed.

\section{Autonomous learning through video clips}

The notion of autonomy is differently conceptualised in different contexts (Davies, 1987). However, the nurturing of learner autonomy as a general educational goal has been widely recognised by the teaching profession (Chan, 2001). Broadly speaking, learner autonomy is seen as the ability or readiness of a learner to take charge of his or her own learning. This entails both a capacity and willingness on the part of the learner to act independently (and in co-operation with others) as a socially responsible person

\footnotetext{
${ }^{2}$ http://www.ru.ac.za/VITALmaths
} 
(Dam, 1995, as cited in Chan, 2001, p. 506). As McCombs and Whisler (1989) comment, in order to become autonomous, learners need to attach personal meaning to learning activities while at the same time they need to develop cognitive and metacognitive capabilities for regulating both affect and motivation. Furthermore, inasmuch as the capacity and willingness for the learner to take such responsibility may not necessarily be innate, it is important to recognise autonomous learning as a developmental phenomenon (McCombs \& Whisler, 1989).

Autonomy represents an inner endorsement of one's actions - a sense that one's actions emanate from within and are one's own (Deci \& Ryan, 1987, as cited in Reeve \& Jang, 2006, p. 209). Teachers cannot directly provide learners with an experience of autonomy (Reeve \& Jang, 2006), but rather they need to provide genuine opportunities that encourage, nurture and support autonomous learning. The VITALmaths project aims to provide just such opportunities through the medium of short video clips.

As Mousley, Lambdin and Koc (2003, p. 425) succinctly comment, "Autonomy is not a function of rich and innovative materials themselves, but relates to genuine freedoms and support given to students." Thus, critical elements of the design principles of the video clips take into account both cognitive and non-cognitive dimensions. These video clips unpack a variety of mathematical concepts which are progressively developed while encouraging a desire to experiment, use trial-and-error, formulate conjectures, and generalise results. Importantly, however, they also encourage and support non-cognitive dimensions of mathematical competence such as curiosity, motivation, a willingness to know, determination to overcome disappointment and frustration, and a willingness to try things again.

The video clips are purposefully made from natural materials, as opposed to high-tech graphics animations, in order to support autonomous learning on two levels. Firstly, in terms of cognitive access, the use of natural materials should allow for a more direct and personally meaningful engagement with the content of the video clips when compared with the additional abstract dimension associated with hightech graphics animations. Secondly, learners will be able to personally source all the required material to explore identical or similar scenarios, thus encouraging hands-on mathematical exploration that will have personal meaning for each learner. Feedback from learners and teachers will be used to continuously refine the design principles of the video clips through a cyclical feedback process. In addition, to further the autonomous learning imperative of the project, our aim is to make these video clips available in a number of different languages, including South African indigenous languages.

\section{Mobile learning}

Specific to the South African context is our interest in the use of cellphone technology as the primary distribution platform for these video clips. Not only will cellphone technology facilitate access to these video materials, but it is likely to enhance and support the autonomous learning objective of the enterprise. There are a variety of mobile devices that have found application within the education arena Personal Digital Assistants (PDAs), PC tablets, iPods, and some games devices. However, fuelled by the development of powerful telecommunication networks which support an ever increasing range of data access services, coupled with technological advances and steadily declining costs of cellphones themselves, cellphones have emerged as a viable option for mobile learning. The VITALmaths project aims to capitalise on the flexible and versatile potential of cellphones for mobile learning.

Selanikio (2008) makes the pertinent comment that "for the majority of the world's population, and for the foreseeable future, the cell phone is the computer" (para. 28). This sentiment is echoed by Ford (2009) in her pronouncement that "the cellphone is poised to become the 'PC of Africa"' (slide 3). The challenge for teachers is thus "to capitalize on the pervasive use of cell phones by younger students for educational purposes" (Pursell, 2009, p. 1219).

The educational potential for mobile learning afforded by cellphone technology is diverse (Kolb, 2008; Prensky, 2005). Within South Africa a number of projects have already harnessed the ubiquity of cellphone technology to support the learning of mathematics. A number of these projects are briefly outlined here in order to contextualise the growing potential for mobile learning through cellphone technology within the South African education landscape. 
ImfundoYami/ImfundoYethu is a mobile learning platform that delivers mathematics education to Grade 10 learners through the instant messaging service MXit. Learners are able to access exercises and additional help. Mathematics teachers log into a web-based management system from which they can distribute exercises to the learners, provide personal support, and monitor both results and learner activity (Vosloo, 2009).

The M4Girls project aims to improve the mathematics performance of Grade 10 female learners in rural schools in South Africa. Learners are provided with cellphones containing a number of mini videos (2-3 minutes in length), mobile episode animations, and games. All mathematical content is aligned with the South African mathematics curriculum (Vosloo, 2008).

$M O B I^{\mathrm{TM}}$ is a proprietary product that can be accessed through most Java-enabled cellphones. The product aims to provide mobile mathematics education to Grade 10 to 12 learners, and the content is specifically tailored for the South African mathematics curriculum (Vosloo, 2007). MOBI ${ }^{\mathrm{TM}}$ maths provides the user with access to tutorials (in the form of streamed videos), past examination papers with solutions, and an opportunity for learners to use closed chat rooms to form study or discussion groups (Botha, 2007).

Dr Math enables learners to access assistance with their homework assignments by interacting with tutors through MXit, a mobile instant messaging platform. In addition, $\mathrm{Dr}$ Math encourages drill and practice of basic skills through games and competitions via the MXit platform (Butgereit, 2009; Vosloo \& Botha, 2009).

\section{Design principles}

Of critical importance to the VITALmaths project are the design principles on which the video clips are modelled. Discussing the design principles of educational software applets, Underwood et al. (2005) highlight the observation that the design of technology tools plays a critical role in terms of how learners interact with the tools. This in turn can have a dramatic affect on the efficacy of the affordances offered by the technological medium.

There are two distinct tiers to the design process, although they are by no means independent of one another. The first relates to the broader design principles of mobile learning in general, while the second relates specifically to the technical details of the video clips themselves.

\section{Broad design principles of mobile learning}

Herrington, Herrington and Mantei (2009) identify a number of broad design principles for mobile learning. Of particular relevance to the VITALmaths project, specifically in relation to the autonomous learning initiative of the project, are the following five, each of which is briefly discussed in relation to the project:

Use mobile learning in non-traditional learning spaces

The video clips are specifically designed to foster and support non-cognitive dimensions such as curiosity, motivation, and a willingness to know. It is thus envisaged that learners (and teachers) will be inspired to view these video clips in non-traditional learning spaces - waiting for a bus, travelling home on a mini-bus taxi, standing in a queue etc.

\section{Employ mobile learning in contexts where learners are mobile}

When learners are inspired to explore the scenarios suggested in the video clips, they will be able to act immediately. Their endeavours will not be frustrated by having to return to a computer laboratory, for example, to review the video clip. They will have instant access to the video clip on their own cellphone, and will thus be able to take advantage of the momentum of the given moment.

Make use of mobile learning both individually and collaboratively

The video clips encourage learners to explore, in a hands-on fashion, similar scenarios to those presented in the videos. This can be done either individually or collaboratively, based on the autonomous decision of each learner. 


\section{Exploit the affordances of mobile technologies}

Although the video resolution of a computer is generally greater than that of a cellphone, the affordances offered by mobile technology far outweigh this difference. The graphics resolution of most cellphones is not only sufficient for the purposes of the video clips, but the use of cellphones will ensure that the video clip files are as small as possible (between 500 and 800 kilobytes) which in turn will ensure widespread accessibility.

Employ the learners' own mobile devices.

Finally, if the video clips are able to be downloaded onto each learner's cellphone, not only will there be a heightened individual sense of ownership and autonomy, but this will provide support for the other broad design principles.

\section{Technical details of video clips}

In terms of the design principles that relate specifically to the technical details of the video clips themselves, the video clip "rectangular products" is discussed as an example. The video clip makes use of geometric algebra (Suzuki, 2009) to give elegant visual support of the distributive property. The film first presents the result that $26 \times 38=988$. The suggestion is then made that 26 and 38 can be expressed as $20+6$ and $30+8$ respectively. This scenario is then presented visually as shown in Figure 1 .

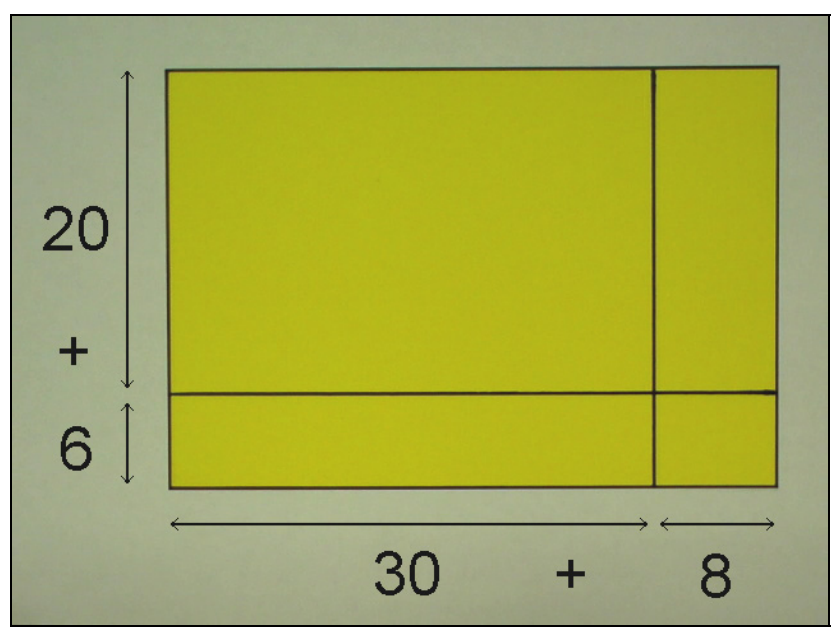

Figure 1: Frame 25 from the video clip "rectangular products"

The large 26 by 38 rectangle is then separated, using animated movement, into four smaller rectangles. The area of each rectangle is then calculated as shown in Figure $2 .^{3}$

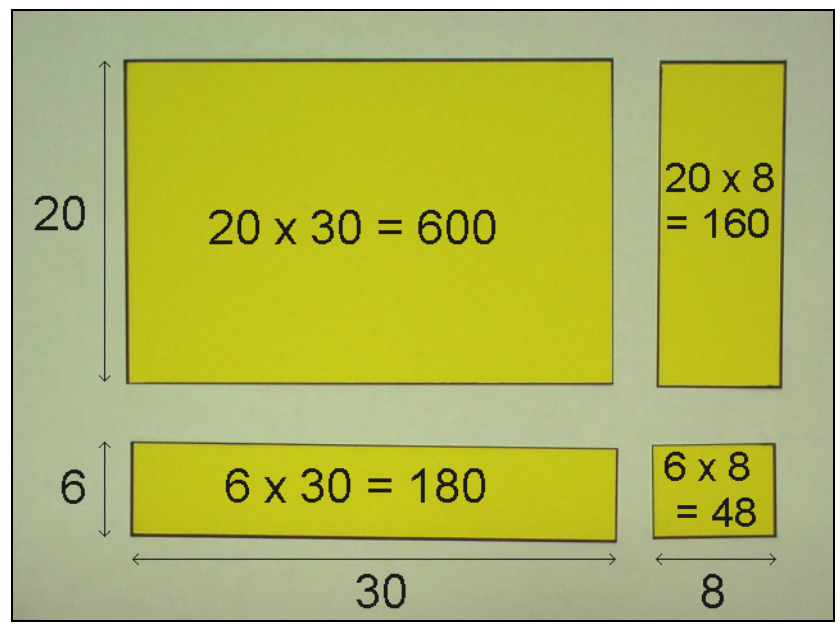

Figure 2: Frame 35 from the video clip "rectangular products"

\footnotetext{
${ }^{3}$ The reader will notice that the rectangles are not all perfectly aligned. That is because the video clips are not computer animations, but are produced using natural materials, in this case real paper cut-outs.
} 
The sum of the areas of the four rectangles is then shown to be the same as the original product, i.e. $26 \times 38=600+180+160+48=988$. The question is then posed as to whether a similar approach could be used to determine the product of 3-digit numbers or even the product of algebraic expressions.

This video clip develops a particular mathematical theme in a progressive manner. However, it does so in a way that is purposefully not underpinned by specific pedagogical imperatives or predetermined outcomes. Indeed, terms such as distributive property are purposefully avoided so as to ensure maximum flexibility of the material, and to broaden the context (e.g. grade-specificity) of its usefulness. Teachers and learners are thus encouraged to use the video clip as autonomously as they desire. This wish is in turn supported by the broad and open philosophy embraced by the design principles on which the video is conceived.

"Rectangular products" purposefully refrains from giving specific instructions for repeating or extending the exercise with different numbers. However, it closes with probing questions that encourage extension and experimentation in a spirit of mathematical exploration. This video clip is short in duration (1 minute 48 seconds), small in terms of file size (646 kilobytes in MP4 format; 519 kilobytes in 3G2 format), but is nonetheless aesthetically delightful and self-explanatory. The MP4 format is suitable for PCs, iPods, iPhones and many modern cellphones, while the $3 \mathrm{G} 2$ format is designed specifically for use on older or more basic cellphones.

\section{Concluding comments}

The VITALmaths project aims to develop visual technologies for autonomous learning in mathematics and research their efficacy and impact in order to ensure sustained development in mathematics education in South Africa and Switzerland. In particular, the specific use and application of cellphone technology will be explored. It is anticipated that this innovation will have a significant positive impact for teachers in deep rural settings where access to mathematics resources is very limited.

The project seeks to capitalise on the versatility and ubiquity of cellphone technology to provide a mathematics platform to store and disseminate short mathematical video clips that can be used both as teaching and motivational resources. Since a large cross-section of teachers will be accessing these video clips it is important that the videos embrace a broad and open philosophy, and that they avoid pedagogical imperatives that render them useful only in narrow contexts. It is envisaged that these video clips will be used in the preparation of lessons, for personal conceptualisation of mathematical concepts, and as motivational and explanatory tools, with the emphasis lying on teachers and learners to use them as autonomously and independently as they wish.

In order for the videos to be used as autonomously as possible, they need to be short, succinct, visually and intellectually appealing, relevant and mathematically inspirational. A growing databank of video clips has already been produced. Feedback from teachers and learners relating to the efficacy, use and impact of these video clips is being used to continuously refine the design principles that inform their conceptualisation and production.

Continued research into the use and impact of these video clips seeks to develop a base for sustained growth and development, while at the same time contributing and participating in the academic discourse surrounding the use and development of visual technologies in the mathematics education arena.

\section{Acknowledgement}

This work is based upon research supported by the FirstRand Foundation Mathematics Education Chairs Initiative of the FirstRand Foundation, Rand Merchant Bank and the Department of Science and Technology, as well as the Swiss South African Joint Research Programme.

Any opinion, findings, conclusions or recommendations expressed in this paper are those of the authors and therefore the FirstRand Foundation, Rand Merchant Bank and the Department of Science and Technology do not accept any liability with regard thereto. 


\section{References}

Botha, A. (2007, August 1). Mobile education. Mail \& Guardian Online. Retrieved from http://www.mg.co.za/article/2007-08-01-mobile-education

Butgereit, L. (2009). Using text adventure games to entice learners to practice arithmetic skills over Mxit. In J. H. Meyer \& A. Van Biljon (Eds.), Proceedings of the $15^{\text {th }}$ Annual Congress of the Association of Mathematics Education of South Africa (Vol. 2, pp. 3-10). Bloemfontein: AMESA. Available at http://www.amesa.org.za/amesa2009/Proceedings.htm

Chan, V. (2001). Readiness for learner autonomy: What do our learners tell us? Teaching in Higher Education, 6(4), 505-518. doi: 10.1080/13562510120078045

Davies, W. J. K. (1987). Towards autonomy in learning: Process or product? London: Council for Educational Technology.

Department of Education (2002). Revised national curriculum statement Grades R-9 (Schools): Mathematics. Pretoria: Government Printer.

Department of Education (2003). National curriculum statement Grades 10-12 (General): Mathematics. Pretoria: Government Printer.

Ford, M. (2009, June). Dr Math - A mobile tutoring platform for Africa? [PowerPoint slides]. Paper presented at the SAFIPA (South Africa-Finland Knowledge Partnership on ICT) conference. Pretoria, South Africa. Retrieved from http://mlearningafrica.net/wp-content/uploads/2009/06/drmath_safipa2009_merrylford.ppt

Herrington, A., Herrington, J., \& Mantei, J. (2009). Design principles for mobile learning. In J. Herrington, A. Herrington, J. Mantei, I. Olney, \& B. Ferry (Eds.), New technologies, new pedagogies: Mobile learning in higher education (pp. 129-138). Wollongong: University of Wollongong. Retrieved from http://ro.uow.edu.au/cgi/viewcontent.cgi?article=1089\&context=edupapers\&sei-redir=1\#search="'Herrington, +A.,+Herrington, + J., +\&+Mantei"'"

Klieme, E., Avenarius, H., Blum, W., Döbrich, P., Gruber, H., Prenzel, M., ... Vollmer, H. J. (2004). The development of national educational standards: An expertise. Berlin: Federal Ministry of Education and Research. Retrieved from http://www.bmbf.de/pub/the_development_of_national_educationel_standards.pdf

Kolb, L. (2008). Toys to tools: Connecting student cell phones to education. Washington, DC: International Society of Technology in Education.

Linneweber-Lammerskitten, H., \& Schäfer, M. (2010). Motivating mathematical exploration through the use of video-clips: A collaborative research and development project between Switzerland and South Africa. In V. Mudaly (Ed.), Proceedings of the $18^{\text {th }}$ Annual Meeting of the Southern African Association for Research in Mathematics, Science and Technology Education (Vol. 2, pp. 161-164). Pinetown: SAARMSTE. Available at http://www.sdu.uct.ac.za/usr/sdu/downloads/conferences/saar_mste2010/shortpapervol2.pdf

Linneweber-Lammerskitten, H., \& Wälti, B. (2008). HarmoS mathematik: Kompetenzmodell und vorschläge für bildungsstandards [HarmoS mathematics: Competency model and suggestions for educational standards]. Beiträge zur Lehrerbildung, 26(3), 326-337. Retrieved from http://www.bzlonline.ch/archivdown load/artikel/BZL_2008_3_326-337.pdf

McCombs, B. L., \& Whisler, J. S. (1989). The role of affective variables in autonomous learning. Educational Psychologist, 24(3), 277-306. doi: 10.1207/s15326985ep2403_4

Mousley, J., Lambdin, D., \& Koc, Y. (2003). Mathematics teacher education and technology. In A. J. Bishop, M. A. Clements, C. Keitel, J. Kilpatrick, \& F. K. S. Leung (Eds.), Second international handbook of mathematics education (pp. 395-432). Dordrecht: Kluwer Academic Publishers.

OECD (2003). Definition and selection of competencies: Theoretical and conceptual foundations (DeSeCo). Summary of the final report: Key competencies for a successful life and a well-functioning society. Paris: OECD.

Prensky, M. (2005). What can you learn from a cell phone? Almost anything! Innovate, 1(5). Retrieved from http://www.innovateonline.info/pdf/vol1_issue5/What_Can_You_Learn_from_a_Cell_Phone_Almost_An ything!.pdf

Pursell, D. P. (2009). Adapting to student learning styles: Engaging students with cell phone technology in organic chemistry instruction. Journal of Chemical Education, 86(10), 1219-1222. doi: $10.1021 /$ ed086p 1219

Reeve, J., \& Jang, H. (2006). What teachers say and do to support students' autonomy during a learning activity. Journal of Educational Psychology, 98(1), 209-218. doi:10.1037/0022-0663.98.1.209

Selanikio, J. (2008, January 17). The invisible computer revolution. BBC News. Retrieved from http://news.bbc.co.uk/go/pr/fr/-/2/hi/technology/7106998.stm

Suzuki, J. (2009). Modern geometric algebra: A (very incomplete!) survey. Mathematics Teacher, 103(1), 26-33. Retrieved from http://www.nctm.org/eresources/view_media.asp?article_id=8874 
Underwood, J. S., Hoadley, C., Lee, H. S., Hollebrands, K., DiGiano, C., \& Renninger, K. A. (2005). IDEA: Identifying Design Principles in Educational Applets. Educational Technology Research and Development, 53(2), 99-112. doi: 10.1007/BF02504868

Vosloo, S. (2009). ImfundoYami/ImfundoYethu: Mobile learning for mathematics. Retrieved from $\mathrm{http}: / /$ mlearningafrica.net/category/projects/

Vosloo, S. (2007). MOBI ${ }^{\mathrm{TM}}$. Retrieved from http://mlearningafrica.net/category/projects/

Vosloo, S. (2008). M4Girls. Retrieved from http://mlearningafrica.net/category/projects/

Vosloo, S., \& Botha, A. (2009, June). Mobile learning: South African examples. Paper presented at the Mobile Learning Institute Summit. Lusaka, Zambia. Retrieved from http://www.slideshare.net/stevevosloo/mobilelearning-south-african-examples

Wittmann, E. Ch. (1995). Mathematics as a 'design science'. Educational Studies in Mathematics, 29(4), 355374. doi: 10.1007/BF01273911 